\title{
Analisis Perpindahan Panas Pada Heat Exchanger Di Furnace Boiler Circulating Fludizing Bed Unit 1 Pltu Nagan Raya 2 X 110 Mw
}

\author{
Maidi Saputra ${ }^{1}$, Ari Ferdian Syah ${ }^{2}$ \\ ${ }^{1}$ Dosen Teknik Mesin - Universitas Teuku Umar - Meulaboh E- \\ mail :maidisaputra@utu.ac.id \\ ${ }^{2}$ Pegawai PLTU Sektor Nagan Raya 2x110 MW \\ E-mail : ariferdian27@gmail.com
}

\begin{abstract}
Abstrak
Sistem tenaga listrik terdiri atas pembangkitan, penyaluran dan distribusi. Salah satu jenis pembangkit adalah Pembangkit Listrik Tenaga Uap (PLTU). Komponen-komponen utama dalam PLTU adalah ketel uap (Boiler), Turbin Uap, Kondenser dan Generator sinkron. Perpindahan panas yang terjadi di dalam beberapa Heat Exchanger pada Furnace Boiler Ciruculating Fludizing Bed (CFB) terjadi dengan Konduksi, Konveksi maupun Radiasi. Tujuan penelitian ini untuk menghitung dan membandingkan nilai Koefisien Perpindahan Panas dan banyaknya Kalor yang Diserap selama proses penelitian atau Nilai Aktual dengan proses Komisioning pada Heat Exchanger di Furnace Boiler (Wall tube atau HE, Evaporator atau $\mathrm{HE}_{2}$, dan Platen Superheater atau $H E_{3}$ ). Pengumpulan data dilakukan dengan metode observasi. Pengolahan data untuk menghitung nilai Koefisien Perpindahan panas dan banyaknya kalor yang diserap terlebih dahulu dengan menghitung beda temperatur dengan metode Log Mean Difference Temperature (LMDT) dan juga bilangan Nusselt dan Reynold untuk masing-masing Heat Exchanger pada kondisi Aktual dan komisioning. Selanjutnya didapatkan nilai perhitungan untuk Koefisien Perpindahan Panas pada $\mathrm{HE}_{1}$ Aktual dan komisioning sebesar 0,598 $\mathrm{W}^{2} \mathrm{~m}^{2}{ }^{0} \mathrm{C}$, pada $\mathrm{HE}_{2}$ Aktual dan Komisioning sebesar $0,829 \mathrm{~W} / \mathrm{m}^{2}{ }^{\circ} \mathrm{c}$, pada $\mathrm{HE}_{3}$ Aktual sebesar $0,779 \mathrm{~W} / \mathrm{m}^{2}{ }^{0} \mathrm{c}$ dan Komisioning sebesar $0,8 \mathrm{~W} / \mathrm{m}^{2}{ }^{\circ} \mathrm{c}$, dan banyaknya kalor yang diserap pada $\mathrm{HE}_{1}$ Aktual sebesar 88,515 KJ/Kg dan Komisioning sebesar 11,99 KJ/Kg, pada $\mathrm{HE}_{2}$ Aktual sebesar 1,73 KJ/Kg dan Komisioning sebesar 1,44 KJ/Kg, pada $\mathrm{HE}_{3}$ Aktual sebesar 271,06 KJ/Kg dan Komisioning sebesar 72,82 KJ/Kg.
\end{abstract}

Kata Kunci : Furnace Boiler, Heat Exchanger, LMDT, koefisien panas menyeluruh, kalor yang diserap

\section{PENDAHULUAN}

Penggunaan listrik merupakan kebutuhan yang sangat penting pada kehidupan manusia sekarang ini. Sebuah pembangkit listrik seperti PLTU merupakan hal utama yang harus ditunjang dengan berbagai peralatan utama (Boiler, Turbin dan Generator) untuk menghasilkan listrik.

Setiap Boiler yang digunakan di PLTU pada dasarnya memiliki struktur dan komponen penunjang. Hal ini dikarenakan penggunaan boiler disesuaikan dengan beban yang dihasilkan dan jumlah karbon batubara yang digunakan sebagai bahan bakar utama pada proses pembakaran. 


\section{Jurnal Mekanova \\ Vol 4. No. 1, April 2018 \\ ISSN : 2502-0498}

Pengoperasian yang terus menerus yang dilakukan oleh sebuah unit Boiler ini mengakibatkan berbagai permasalahan yang komplek terjadi pada unit Boiler itu sendiri maupun berbagai peralatan penunjang pada pengoperasian Boiler, salah satunya tidak optimalnya pengoperasian suatu peralatan utama maupun penunjang (perpindahan panas yang terjadi didalam Furnace Boiler tidak terjadi dengan sempurna) yang ditimbulkan karena munculnya berbagai pengerakan di pipa-pipa Heat Exchanger dan juga tidak optimalnya penyerapan panas pada Heat Exchanger.

Beberapa permasalahan utama yang akan dibahas antara lain berapa nilai koefisien perpindahan kalor secara keseluruhan yang terjadi di dalam Furnace Boiler pada Wall tube unit 1 PLTU Nagan Raya, berapa nilai koefisien perpindahan kalor secara keseluruhan pada Heat Exchanger (Evaporator dan Plalten Superheater) yang terdapat di Furnace Boiler unit 1 PLTU Nagan Raya dan berapa nilai kalor yang diserap di setiap Heat Exchanger pada Furnace Boiler unit 1 PLTU Nagan Raya.

Penelitian ini bertujuan mengetahui sistem pembakaran di Boiler yang terjadi pada Pembangkit Listrik Tenaga Uap (PLTU) unit 1 Nagan Raya, menghitung nilai koefisien perpindahan panas keseluruhan di Furnace Boiler pada Wall tube, Evaporator dan Platen Superheater unit 1 PLTU Nagan Raya serta membandingkan nilai koefisien perpindahan panas keseluruhan di furnace boiler selama proses penelitian dengan data-data selama proses komisioning (data awal).

\section{Boiler}

Boiler adalah salah satu peralatan utama dari PLTU yang berfungsi untuk merubah air menjadi uap superheat yang bertemperatur dan bertekanan tinggi. Proses memproduksi uap ini disebut Pembuat Uap (Steam Raising). Unit atau alat yang digunakan untuk membuat uap disebut Boiler atau lebih tepat Pembangkit Uap (Steam Generator).

Klasifikasi Boiler secara umum dibagi dua yaitu, boiler pipa api dan boiler pipa air. Jenis boiler pipa api banyak digunakan oleh industri yang memerlukan tekanan uap yang relatif rendah, misalnya pabrik-pabrik gula. Sedangkan jenis pipa air digunakan oleh industri atau pembangkit listrik yang memerlukan tekanan uap yang tinggi, misalnya pada pusat-pusat listrik tenaga uap. (Yendri. 2011).

\section{Jenis-jenis Boiler a)}

Boiler Pipa Api

Pada jenis Boiler pipa api, gas panas hasil pembakaran (flue gas) mengalir melalui pipa-pipa yang di bagian luarnya diselimuti air sehingga terjadi perpindahan panas dari gas panas ke air dan air berubah menjadi uap. Gambar 1 menunjukan boiler pipa api. 
Jurnal Mekanova

Vol 4. No. 1, April 2018

ISSN : 2502-0498

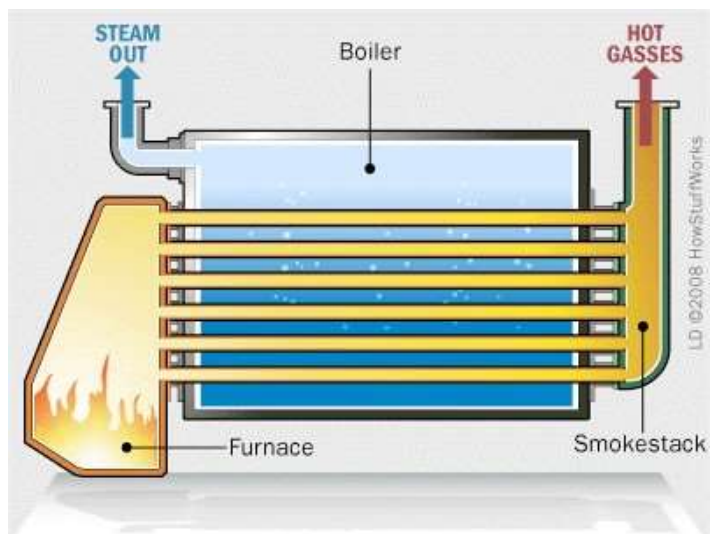

Gambar 1. Boiler pipa api

(Sumber: Yendri, 2011)

b) Boiler Pipa Air

Pada boiler jenis ini, air berada di dalam pipa sedangkan gas panas berada di luar pipa. Boiler pipa air dapat beroperasi dengan tekanan sangat tinggi (lebih dari $100 \mathrm{Bar}$ ). Gambar Boiler pipa air dapat dilihat pada gambar 2.

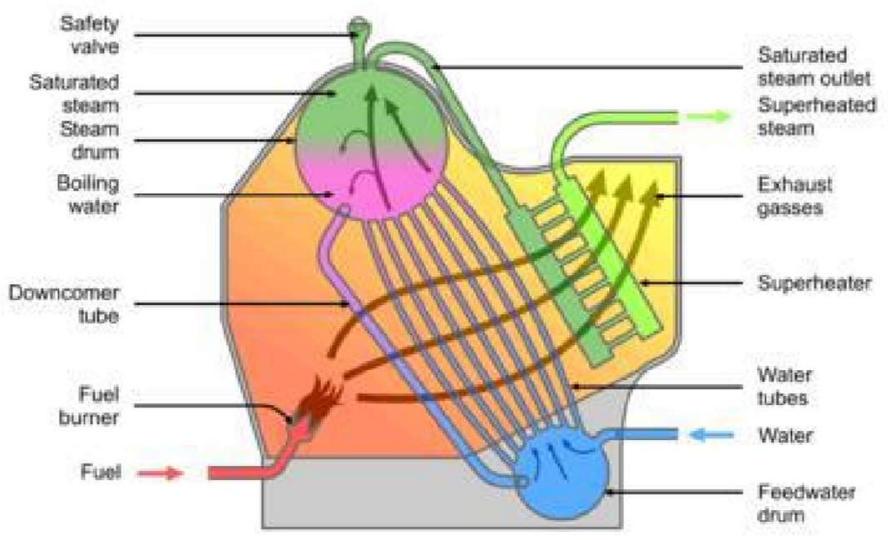

Gambar 2. Boiler pipa air (Sumber:

Yendri, 2011)

c) Boiler Jenis Stoker

Pada boiler Stoker pembakarannya ditempatkan di atas rantai seperti rantai tank yang berjalan, serta bentuk-bentuk modifikasinya. Boiler jenis ini mempunyai efisiensi antara $80 \%-85 \%$. 
Jurnal Mekanova

Vol 4. No. 1, April 2018

ISSN : 2502-0498

d) Boiler Jenis Pulverizer

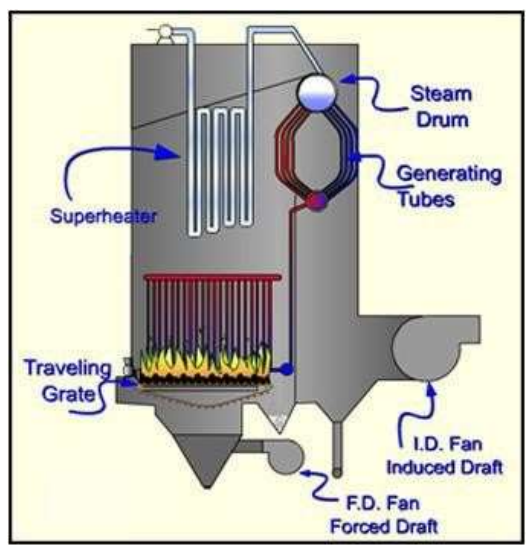

Gambar 3. Boiler jenis stoker (Sumber:

Yendri, 2011)

Boiler jenis pulverizer, sering disebut PC (Pulverizer Combustion) Boiler. Batu bara ditepungkan terlebih dahulu kemudian disemprotkan ke ruang bakar sehingga mengapung dan terbakar di tengah-tengah ruang bakar. Boiler jenis ini mempunyai efisiensi sekitar 90\%. e) Boiler Jenis CFB

Boiler jenis Circulating Fluidize Bed (CFB), boiler ini ukuran diameter batu baranya sekitar $30 \mathrm{~mm}$ dan dilengkapi dengan cyclone diantara ruang bakar dan outlet asapnya. Fungsi cyclone untuk memisahkan (separator) gas untuk dibuang melalui cerobong asap dan partikel yang tidak terbakar untuk dikembalikan ke ruang bakar. Boiler jenis ini efisiensinya sekitar $92 \%$.

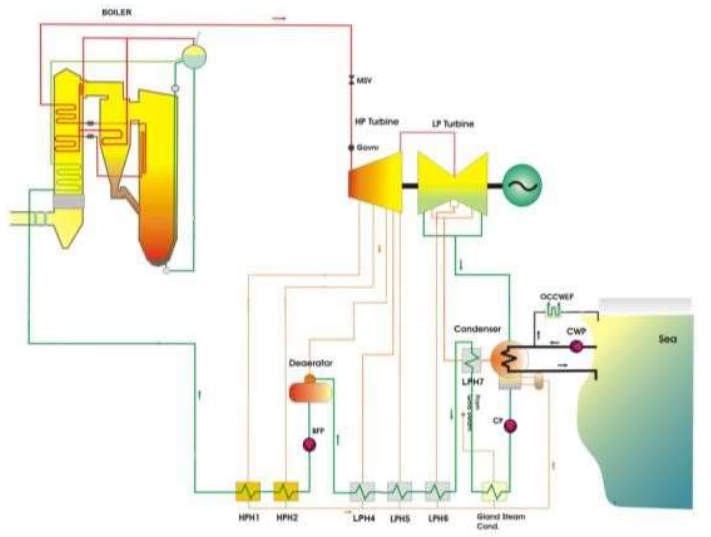

Gambar 4. Boiler jenis CFB

(Sumber: Saputro, 2014)

Prinsip kerja dasar CFB boiler yaitu batu bara dan desulfurizer (limestone) yang disuplai ke dalam furnace kemudian dibakar, dan pada saat itu terjadilah proses desulfurisasi. Batu bara dan desulfurizer ikut terbawa ke atas bersama flue gas dan melepaskan panas ke water wall dan pemukaan penyerap panas yang lain. Partikel-partikel yang berukuran besar, jatuh kembali ke furnace karena beratnya sendiri, sedangkan partikel yang berukuran kecil masuk ke dalam cyclone separator. Campuran zat padat dan gas yang masih berukuran besar akan jatuh ke bawah cyclone separator dan dikembalikan lagi ke dalam furnace untuk dibakar kembali. Sedangkan partikel-partikel halus akan terbang bersama flue gas menuju back pass/heat recovery area untuk memanaskan superheater, 


\section{Jurnal Mekanova}

Vol 4. No. 1, April 2018

ISSN : 2502-0498

economizer dan air heater. Setelah itu flue gas akan dibuang ke udara atmosfer setelah melewati electrostatic presipitator (Djokosetyardjo 2006).

\section{Bagian-bagian Boiler dan Alat Bantunya a) \\ Ruang Bakar}

Ruang bakar adalah bagian dari Boiler yang berfungsi untuk tempat berlangsungnya proses pembakaran antara bahan bakar dan udara. Tekanan gas panas yang berada di dalam ruang bakar (Furnace) dapat lebih besar dari pada tekanan udara luar (tekanan ruang bakar positif) dan dapat juga bertekanan lebih kecil dari tekanan udara luar (tekanan ruang bakar negatif) atau bertekanan seimbang (Balance Draught). b) Soot Blower (Pembersih Jelaga)

Boiler-boiler modern dilengkapi dengan pembersih jelaga (soot blower) yang dapat dioperasikan dari jarak jauh (remotely operated) dan dikendalikan secara bergantian dan berurutan. Fungsi dari soot blower adalah untuk membersihkan abu, debu atau jelaga yang menempel pada pipa-pipa boiler, superheater, economizer dan pada elemen air heater. Tujuan dari pembersihan tersebut adalah untuk menaikkan efisiensi dari boiler dan menghindari kerusakan pipa-pipa pada boiler atau superheater. Biasanya soot blower menggunakan uap untuk membersihkan pipa-pipa boiler atau superheater. c) Burner

Burner adalah alat yang dipakai untuk memasukkan bahan bakar minyak kedalam ruang bakar dan menghasilkan pengabutan yang memudahkan reaksi pembakaran. d) Fan

Penggunaan fan pada PLTU batu bara lebih dari satu jenis, yaitu Induce Draft fan, Force Draft fan, Primary Air fan dan ada pula yang dilengkapi dengan Gas Recirculation fan. Force Draft fan berfungsi sebagai pemasok udara pembakaran kedalam ruang bakar. Indruce Draft fan berfungsi menarik atau mempertahankan tekanan di ruang bakar (pengendali tekanan ruang bakar).

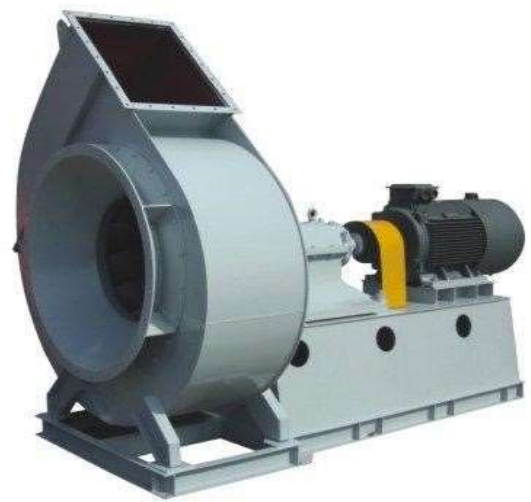

Gambar 5. Fan Sentrifugal

(Sumber: Yendri, 2011)

\section{Bahan Bakar Batu Bara}

Batu bara pada PLTU adalah sebagai bahan bakar utama. Persediaan batu bara ditampung di lapangan terbuka (coal stock area) dan untuk melayani kebutuhan pembakaran di boiler, batu bara ditampung pada bunker (silo) di tiap boiler. Pemasokan batu bara dari bunker ke burner ruang bakar dilakukan melalui coal feeder, mill pulveriser, dan coal pipe. Pengaturan dan pencatatan jumlah aliran batu bara dilakukan dengan coal feeder. Mill pulveriser berfungsi untuk menggerus batu bara sehingga menjadi bubuk. Sedang untuk 
Jurnal Mekanova

Vol 4. No. 1, April 2018

ISSN : 2502-0498

membawa bubuk batu bara ke burner, dihembuskan udara primer ke mill. Udara primer dihasilkan oleh primary air fan (PAF) dan dipanaskan pada pemanas udara primer sehingga cukup untuk mengeringkan bubuk batu bara. Tabel 1. Spesifikasi ASTM Untuk Bahan Bakar Padat

\begin{tabular}{|c|c|c|c|c|c|}
\hline \multirow{2}{*}{ Class } & \multicolumn{2}{|l|}{ Group } & \multirow{2}{*}{$\begin{array}{l}\begin{array}{c}\text { Fixed } \\
\text { carbon }\end{array} \\
\text { Dry \% }\end{array}$} & \multirow{2}{*}{$\begin{array}{c}\begin{array}{c}\text { Volatile } \\
\text { matter }\end{array} \\
\text { Dry } \%\end{array}$} & \multirow{2}{*}{$\begin{array}{c}\text { Heating } \\
\text { values }\end{array}$} \\
\hline & Name & Symbol & & & \\
\hline \multirow{3}{*}{ I. Anthrecite } & Meta-anthrecite & ma & $>98$ & $>2$ & 7740 \\
\hline & Anthrecite & an & $92-98$ & $2.0-8.0$ & 8000 \\
\hline & Semianthrecite & $\mathrm{sa}$ & $86-92$ & $8.0-15$ & 8300 \\
\hline \multirow{6}{*}{ II. Bituminous } & Low-volatile & lvb & $78-86$ & $14-22$ & 8741 \\
\hline & Medium volatile & $\mathrm{mvb}$ & $89-78$ & $22-31$ & 8640 \\
\hline & High-volatile A & hvAb & $<69$ & $>31$ & 8160 \\
\hline & High-volatile B & $\mathrm{hvBb}$ & 57 & 57 & $\begin{array}{l}6750- \\
8180\end{array}$ \\
\hline & \multirow{2}{*}{ High-volatile $\mathrm{C}$} & \multirow{2}{*}{$\mathrm{hvCb}$} & \multirow{2}{*}{54} & \multirow{2}{*}{54} & $\begin{array}{l}7410- \\
8375\end{array}$ \\
\hline & & & & & $\begin{array}{l}6765- \\
7410\end{array}$ \\
\hline \multirow{3}{*}{ III. Subbituminuous } & Subbitumininous A & subA & 55 & 55 & $\begin{array}{c}6880- \\
7540\end{array}$ \\
\hline & Subbitumininous B & subB & 56 & 56 & $\begin{array}{c}6540- \\
7230\end{array}$ \\
\hline & Subbitumininous C & subC & 53 & 53 & $\begin{array}{c}5990- \\
6860\end{array}$ \\
\hline \multirow[t]{2}{*}{ IV. Lignite } & Lignite A & $\operatorname{ligA}$ & 52 & 52 & $\begin{array}{c}4830- \\
6360\end{array}$ \\
\hline & Lignite B & $\operatorname{ligB}$ & 52 & 52 & $<5250$ \\
\hline
\end{tabular}

(Sumber: eprints.polsri.ac.id)

Berdasarkan smart book PT. PLN Persero Pembangkitan Sumatra Bagian Utara Sektor Pembangkitan Nagan Raya terbitan tahun 2014, low calorific power untuk spesifikasi batu bara yang dipakai PLTU Nagan Raya adalah sebesar $3620 \mathrm{Kcal} / \mathrm{Kg}$ (Saputro 2014).

II. METODE PENELITIAN Tempat dan Waktu Penelitian

Penelitian ini dilaksanakan di PT. PLN (Persero) Sektor Pembangkitan Nagan Raya pada PLTU unit 1 dengan kapasitas daya terpasang sebesar 110 MW. Adapun tempat penelitian dilaksanakan di ruang Control Room (CCR) PLTU Nagan Raya dan waktu penelitian dilakukan selama 1 bulan, mulai dari tanggal 1 Oktober 2016 sampai dengan 30 Oktober 2016.

\section{Metode Observasi}

Observasi yang dilakukan pada penelitian ini adalah mengumpulkan semua data yang berhubungan dengan opersional pembangkit listrik, khususnya pada sistem boiler di 


\section{Jurnal Mekanova}

Vol 4. No. 1, April 2018

ISSN : 2502-0498

furnace. Kemudian dilakukan pengambilan data dari ruang pengendali (control room), yaitu data yang berhubungan dengan Boiler combustion system and pembakaran serta data yang berhubungan dengan pembakaran pada furnace boiler cfb.

Berdasarkan perhitungan perpindahan panas yang terjadi dan tampilan dari monitor diruang pengendali (control room) yang berhubungan dengan Boiler pembakaran dan perpindahan panas yang terjadi, maka dibuat tabel parameter PLTU Nagan Raya Unit 1 pada beban pengukuran yang bervariasi, dalam tempo waktu selama proses penelitian berlangsung dari kapasitas daya terpasang untuk mendapatkan nilai perpindahan yang terjadi pada boiler PLTU Nagan Raya unit 1 .

Alat ukur yang dipergunakan dalam penelitian ini adalah semua alat ukur sensor yang terpasang diruang pengendali (control room) dan alat ukur yang terpasang di lapangan.

\section{Analisis Perhitungan}

Perhitungan yang digunakan adalah untuk mendapatkan data yang berhubungan dengan analisis perhitungan perpindahan panas yang terjadi di boiler furnace : a. Menghitung nilai rata-rata parameter

Sebelum melakukan perhitungan nilai koefisien perpindahan panas pada furnace boiler maka terlebih dahulu peneliti menghitung nilai rata-rata parameter pada data logsheet boiler PLTU Nagan Raya selama proses penelitian yang mendukung perhitungan nilai koefisien perpindahan panas pada furnace boiler pltu nagan raya, yaitu dapat dilihat pada tabel di bawah ini:

Tabel 2. nilai rata-rata parameter data log sheet bulan Oktober 2016

\begin{tabular}{|l|c|l|c|}
\hline Beban & $73,94 \mathrm{MW}$ & T ruang HE 1 & $884,4533^{\circ} \mathrm{c}$ \\
\hline T in HE 1 & $280,5267^{\circ} \mathrm{c}$ & T ruang HE $1 \& 2$ & $917,363333^{\circ} \mathrm{c}$ \\
\hline T out HE 1 & $293,7667^{\circ} \mathrm{c}$ & T out ruang & $867,8233^{\circ} \mathrm{c}$ \\
\hline T in HE 2 & $293,7667^{\circ} \mathrm{c}$ & P ruang & $-213,23 \mathrm{~Pa}$ \\
\hline T out HE 2 & $297,0967^{\circ} \mathrm{c}$ & Q air & $283,4133 \mathrm{ton} / \mathrm{h}$ \\
\hline T in HE 3 & $393,2533^{\circ} \mathrm{c}$ & Q uap & $273,23 \mathrm{ton} / \mathrm{h}$ \\
\hline T out HE 3 & $452,3167^{\circ} \mathrm{c}$ & Q udara & $297,6033 \mathrm{KNm} / \mathrm{h}$ \\
\hline P HE 3 & $7,34 \mathrm{MPa}$ & P HE $1 \& 2$ & $8,076667 \mathrm{MPa}$ \\
\hline
\end{tabular}

Sumber : Hasil Observasi

b. Menentukan nilai-nilai perpindahan panas secara konduksi dan konveksi yang terjadi di Furnace

$$
q_{k}=-k A \frac{d T}{d x} q=-h A\left(T_{w}-T_{\infty}\right)
$$

Dengan membandingkan temperatur menggunakan LMDT

$$
\Delta T_{m}=\frac{\left(T_{h 1}-T_{c 1}\right)-\left(T_{c 2}-T_{h 2}\right)}{\ln \frac{\left(T_{h 1}-T_{c 1}\right)}{\left(T_{c 2}-T_{h 2}\right)}}
$$

c. Menentukan nilai bilangan Reynold dan Nusselt 


$$
R e_{x}=\frac{\rho V D}{\mu} N u=3,66+\frac{0,668\left(\frac{D_{i}}{L}\right) R_{e} \cdot P_{r}}{1+0,04\left\{\frac{D_{i}}{L \cdot R_{e} P_{r}}\right\}}
$$

d. Menentukan koefisien perpindahan secara menyeluruh untuk mengetahui berapa panas yang diserap pada masing-masing Heat Exchanger

$$
\begin{aligned}
& U_{0}=\frac{A_{o} \ln \left(\frac{r_{0}}{r_{i}}\right)}{A_{0}+\frac{1}{A}} Q=U \cdot A\left(T_{0}-T_{1}\right) \log \frac{-1}{T-T_{0}} \\
& \frac{A_{0}}{A}+\frac{1}{h_{1}}+\frac{A_{o} \ln \left(\frac{r_{0}}{r_{i}}\right)}{2 \pi k L}+\frac{1}{h_{0}} \\
& 1 \\
& \text { T } T
\end{aligned}
$$

Tabel 3. Nilai-nilai yang ingin diketahui selama penelitian

\begin{tabular}{|c|l|l|l|l|l|l|}
\hline \multirow{2}{*}{$\begin{array}{c}\text { parameter } \\
\text { yang ingin } \\
\text { ditentukan }\end{array}$} & \multicolumn{2}{|c|}{ HE 1(wall tube) } & \multicolumn{2}{c|}{ HE 2 (evaporator) } & \multicolumn{2}{c|}{$\begin{array}{c}\text { HE 3 (platen } \\
\text { superheater) }\end{array}$} \\
\cline { 2 - 7 } & aktual & komisioning & Actual & komisioning & aktual & komisioning \\
\hline $\begin{array}{c}\text { Laju aliran } \\
\text { konduksi }\end{array}$ & & & & & & \\
\hline $\begin{array}{c}\text { laju aliran } \\
\text { radiasi }\end{array}$ & & & & & & \\
\hline $\begin{array}{c}\text { beda suhu } \\
\text { rata-rata }\end{array}$ & & & & & & \\
\hline $\begin{array}{c}\text { koefisien } \\
\text { panas } \\
\text { menyeluruh }\end{array}$ & & & & & & \\
\hline $\begin{array}{c}\text { banyak } \\
\text { kalor yang } \\
\text { diserap }\end{array}$ & & & & & & \\
\hline
\end{tabular}

\section{HASIL DAN PEMBAHASAN Perpindahan Panas Konduksi}

Pembakaran yang terjadi di furnace boiler terjadi perpindahan panas secara konduksi yang dapat dihitung setelah diketahui nilai konduktivitas thermal bahan HE $1=$ $54 \mathrm{~W} / \mathrm{m}^{0} \mathrm{c}$, luas pipa $=1.168,8 \mathrm{~m}^{2}$, beda temperatur $=13,4^{\circ} \mathrm{c}(286,5 \mathrm{~K})$, dan tinggi boiler $=$ $27,7 \mathrm{~m}$.

$$
\begin{gathered}
q_{k}=-k A \frac{d T}{d x} \\
q_{k}=-54 \times 1.168,4 \frac{13,2}{27,7} \\
q_{k}=-29.973,6 \mathrm{~W}
\end{gathered}
$$




\section{Jurnal Mekanova}

Vol 4. No. 1, April 2018

ISSN : 2502-0498

\section{Perpindahan Panas Radiasi}

Perpindahan panas radiasi yang dialami oleh heat exchanger dengan data yang diperoleh antara lain konstanta boltzman $=5,669 \cdot 10^{-8} \mathrm{~W} / \mathrm{m}^{2} \cdot \mathrm{K}^{4}$, luas penampang $=1.164,8$ $\mathrm{m}^{2}$ dan temperatur air pada $\mathrm{HE}=293,7^{\circ} \mathrm{c}$, maka : Qpancaran $=\sigma \mathrm{AT}^{4}$

$\mathrm{Q}_{\text {pancaran }}=5,669.10^{-8} \times 1.164,8 \times\left(293,7^{4}\right)$

$\mathrm{Qpancaran}=491330 \mathrm{~W}$

Menentukan Beda Suhu Rata-Rata (Log Mean Temperature Difference atau LMDT) Dengan diketahui nilai temperatur inlet $\mathrm{He}=280,5^{\circ} \mathrm{c}$, temperatur outlet $\mathrm{He}=293,7^{\circ} \mathrm{c}$, temperatur ruang bakar $=884,4{ }^{\circ} \mathrm{c}$, dan temperatur outlet ruang bakar $=867,8^{\circ} \mathrm{c}$ dengan aliran HE dan ruang bakar searah maka :

$$
\begin{gathered}
\Delta T_{m}=\frac{\left(T_{h 1}-T_{c 1}\right)-\left(T_{c 2}-T_{h 2}\right)}{\ln \frac{\left(T_{h 1}-T_{c 1}\right)}{\left(T_{c 2}-T_{h 2}\right)}} \\
\Delta T_{m}=\frac{(884,4-280,5)-(867,8-293,7)}{(884,4-280,5)} \\
\ln \frac{(867,8-293,7)}{(29,8)} \\
\Delta T_{m}=\frac{(1,051)}{\ln (1,051)} \\
\Delta T_{m}=599,09^{\circ} c
\end{gathered}
$$

\section{Koefisien Perpindahan Panas Menyeluruh}

Untuk mendapatkan nilai koefisien perpindahan panas menyeluruh terlebih dulu harus ditentukan nilai konveksi paksa pipa dalam dan konveksi paksa pipa luar dengan nilai yang telah diketahui yaitu bilangan nusselt $=3,6669$, konduktivitas thermal $=54 \mathrm{~W} / \mathrm{m}^{0} \mathrm{c}$, diameter dalam $=0,054$, maka :

$$
\begin{aligned}
& h_{1}=N u \frac{k}{D_{i}} \\
& h_{1}=3,6669 \frac{54}{0,054} \\
& h_{1}=3666,9 \mathrm{~W} \mathrm{~m}{ }^{0}{ }^{0} \mathrm{c}
\end{aligned}
$$

Dengan nilai kerapatan fluida $=738,2^{3} \quad \mathrm{Kg} / \mathrm{m}$, percepatan gravitasi $=9,8$ $\mathrm{m} / \mathrm{s}^{2}$, konduktivitas thermal $=54 \mathrm{~W} / \mathrm{m}^{0} \mathrm{c}$, diameter luar pipa $=0,06 \mathrm{~m}$, viskositas $=9,51$ $\mathrm{Kg} / \mathrm{ms}$, jumlah pipa pada he $=528$, dan beda temperatur fluida $=13,2^{\circ} \mathrm{c}$ maka :

$$
\begin{gathered}
h_{0}=0,725\left(\frac{\rho^{2} \cdot g \cdot k_{r}{ }^{3}}{\mu \cdot \Delta T \cdot N \cdot D_{0}}\right)^{\overline{4}} \\
h_{0}=0,725\left(\frac{738,2^{2} x 9,8 x 54^{3}}{9,51 x 13,2 x 528 x 0,06}\right)^{\frac{1}{4}} \\
h_{0}=0,725\left(\frac{840921462376,128}{3976,853}\right)^{\frac{1}{4}} \\
h_{0}=87,426 \mathrm{~W} / \mathrm{m}^{2}{ }^{\circ} \mathrm{C}
\end{gathered}
$$

Setelah diketahui nilai konveksi paksa pipa dalam dan konveksi paksa pipa luar maka dengan luas pipa dalam $3,146 \mathrm{~m}^{2}$ dan luas pipa luar $5,23 \mathrm{~m}^{2}$ 


$$
\begin{gathered}
U_{0}=\frac{1}{\frac{A_{0}}{A}+\frac{1}{h_{1}}+\frac{A_{o} \ln \left(\frac{r_{0}}{r_{i}}\right)}{2 \pi k L}+\frac{1}{h_{0}}} \\
U_{0}=\frac{\frac{1}{\frac{5,23}{3,146}+\frac{1}{3666,9}+\frac{5,23 \ln \left(\frac{0,03}{0,027}\right)}{2 \pi \times 54 \times 27,75}+\frac{1}{87,426}}}{U_{0}=\frac{1}{1,66+0,000273+\frac{0,551}{9415,35}+0,011438}} \\
U_{0}=0,598 \frac{W}{m^{2}{ }^{0} c}
\end{gathered}
$$

\section{Jumlah Kalor Yang Diserap}

Setelah diketahui nilai koefisien perpindahan panas secara menyeluruh maka untuk mengetahui jumlah kalor yang diserap oleh fluida di he adalah :

$$
\begin{gathered}
Q=U \cdot A\left(T_{0}-T_{1}\right)\left(\log \frac{T-T_{1}}{T-T_{0}}\right) \\
Q=0,9 \times 1164,8(293,7-280,5)\left(\log \frac{884,4-280,5}{884,4-293,7}\right) \\
Q=13879,75\left(\log \frac{603,9}{590,7}\right) \\
Q=88,515 \frac{K J}{K g}
\end{gathered}
$$

\section{Pembahasan}

Setelah dilakukan berbagai perhitungan dengan data aktual yang telah dikumpulkan maka dibandingkan dengan data selama proses komisioning, berikut adalah perbandingan data Heat Exchanger antara data aktual dan komisioning dalam bentuk grafik dibawah ini :

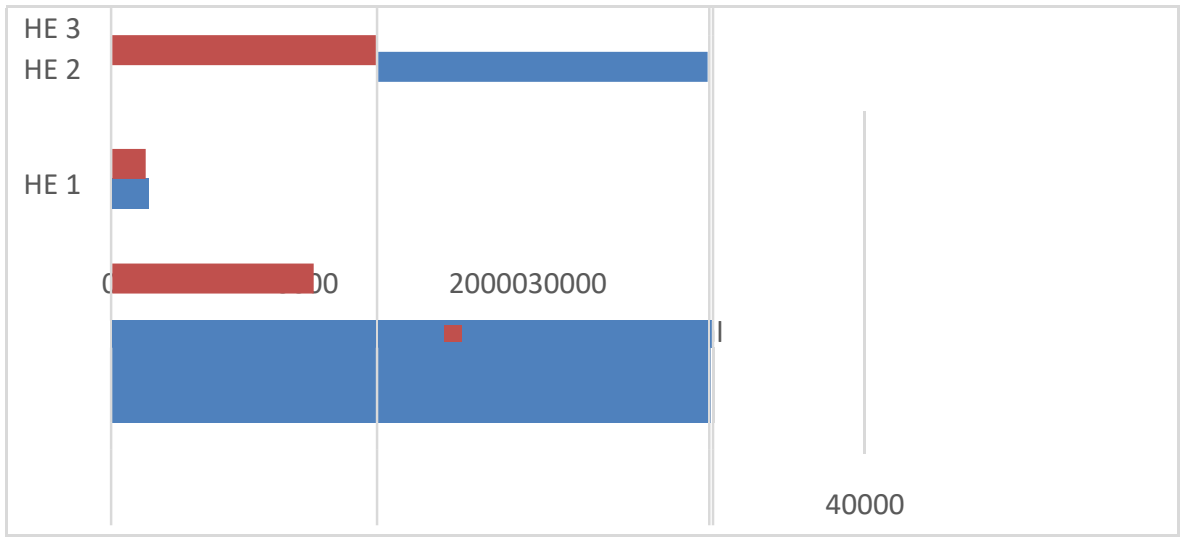

Gambar 6. Laju aliran konduksi (W)

Laju aliran konduksi yang terjadi adalah HE $1=-29.973,6 \mathrm{~W}$, HE $2=-1.925,56 \mathrm{~W}$ dan HE $3=-27.426,47 \mathrm{~W}$ tanda minus (-) pada hasil perhitungan menunjukkan bawah panas berpindah dari temperatur tinggi (ruang bakar) menuju ke temperatur rendah (fluida kerja), tingginya laju aliran konduksi pada HE 1 disebabkan karena luasnya penampang pada HE 1 yang melingkari furnace boiler sedangkan untuk HE 2 dan 3 yang memiliki 


\section{Jurnal Mekanova}

Vol 4. No. 1, April 2018

ISSN : 2502-0498

perbedaan yang jauh adalah dikarenakan jumlah pipa yang lebih banyak pada HE 3 dan perbedaan marerial yang digunakan.

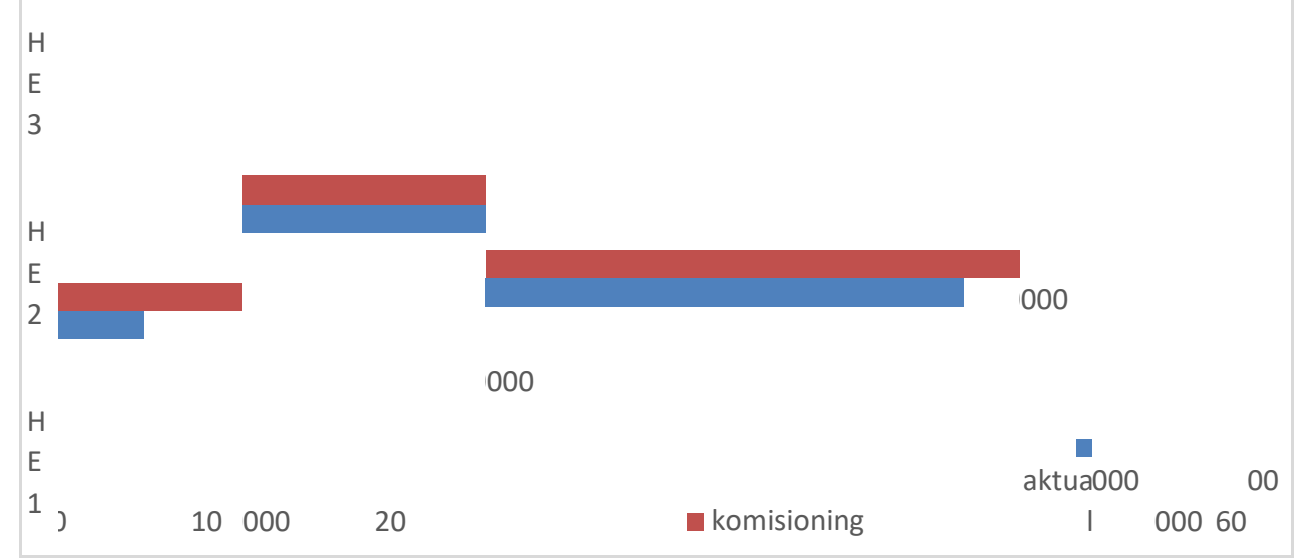

Gambar 7. Laju aliran pancaran radiasi (W)

Laju pancaran radiasi yang terjadi pada HE $1=41.330 \mathrm{~W}$, HE $2=51.939 \mathrm{~W}$ dan HE $3=262.117 \mathrm{~W}$ yang menunjukkan tingginya pancaran pancaran radiasi pada HE 3 yang dipengaruhi oleh temperatur fluida kerja yang dihasilkan pada HE tersebut dan juga fluida kerja pada HE 3 yang telah berupa uap kering berbeda dengan HE 1 dan 2 yang memiliki fluida kerja berupa air yang akan berubah menjadi uap.

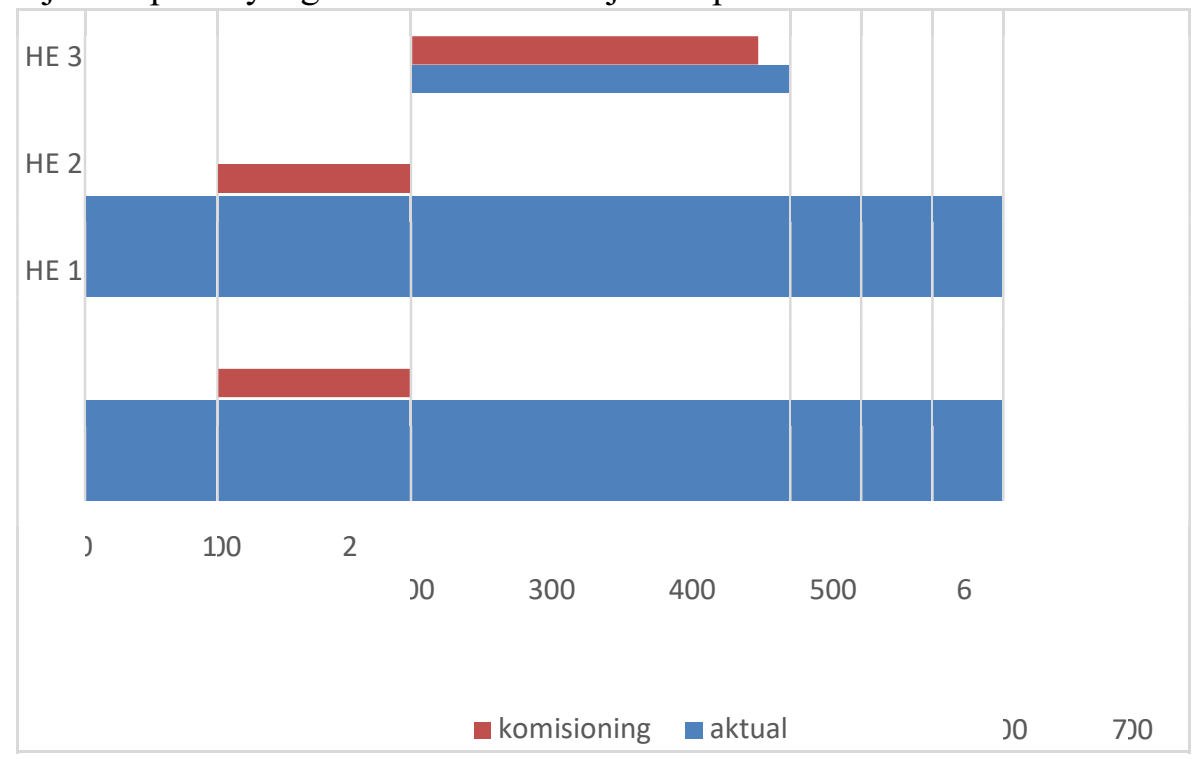

Gambar 8. Beda suhu rata-rata LMDT $\left({ }^{0} \mathrm{c}\right)$

Beda suhu rata-rata yang diukur dengan metode LMDT yang terjadi pada HE $1=$ $599,09{ }^{\circ} \mathrm{c}$, HE $2=599,92{ }^{\circ} \mathrm{c}$ dan HE $3=468,2^{\circ} \mathrm{c}$ yang digunakan untuk menentukan kekuatan pendorong suhu untuk perpindahan panas dalam sistem aliran, terutama pada Heat exchangers. LMTD adalah rata-rata logaritma dari perbedaan suhu antara aliran panas dan dingin di setiap akhir Heat exchanger. Semakin besar LMTD, semakin banyak panas yang ditransfer. Dengan HE 1 dan 2 yang memiliki jumlah panas yang ditransfer hampir sama. 


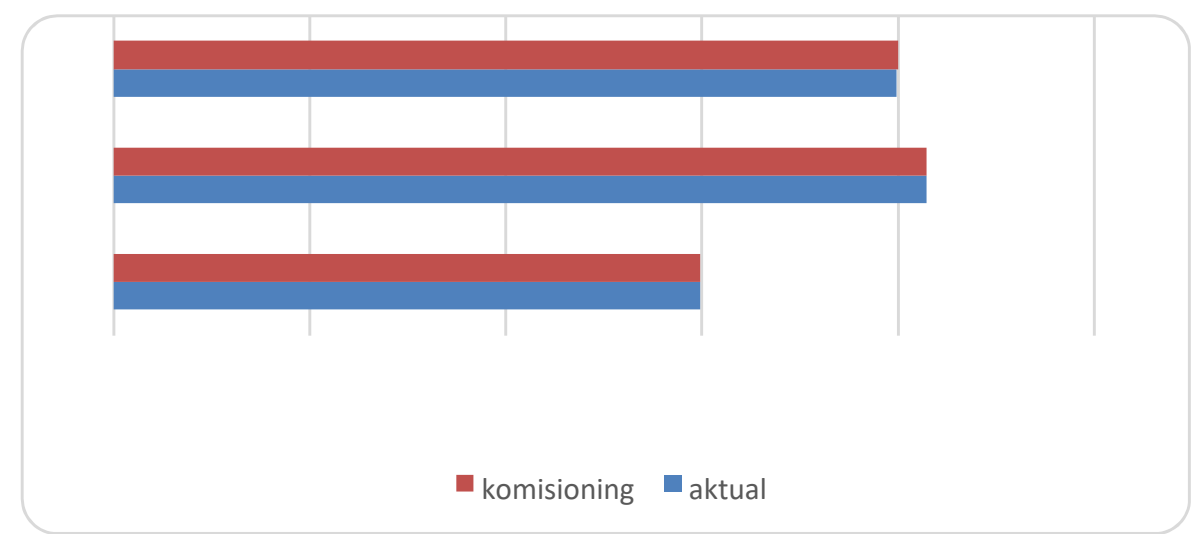

Gambar 9. Koefisien perpindahan panas menyeluruh $\left(\mathrm{W} / \mathrm{m}^{2}{ }^{0} \mathrm{c}\right)$

Koefisien panas menyeluruh yang terjadi di setiap HE memiliki nilai yang sama HE $1=0,598 \mathrm{~W} / \mathrm{m}^{2}{ }^{0} \mathrm{c}$, HE $2=0,829 \mathrm{~W} / \mathrm{m}^{2}{ }^{0} \mathrm{c}$, dan HE $3=0,799 \mathrm{~W} / \mathrm{m}^{2}{ }^{0} \mathrm{c}$ dengan HE 3 memiliki nilai koefisien panas menyeluruh yang lebih besar juga disebabkan oleh material Heat Exchanger dan fluida kerja yang berbeda dengan HE 1. Hal ini juga didefinisikan juga sebagai koefisien hambatan termal total menuju perpindahan panas diantara dua fluida.

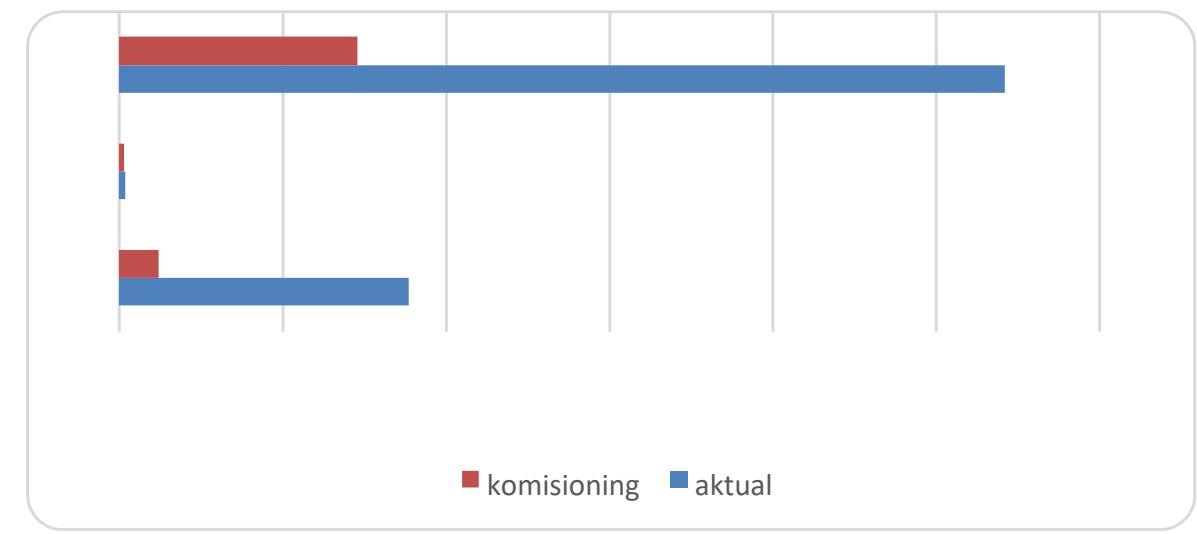

Grafik 10. Banyak kalor yang diserap $(\mathrm{KJ} / \mathrm{Kg})$

Banyaknya kalor yang diserap untuk setiap Heat Exchanger adalah HE $1=88,515$ $\mathrm{KJ} / \mathrm{Kg}, \mathrm{HE} 2=1,73 \mathrm{KJ} / \mathrm{Kg}$ dan $\mathrm{HE} 3=271,06 \mathrm{KJ} / \mathrm{Kg}$ dengan banyaknya kalor yang diserap pada HE 3 juga dikarenakan material yang digunakan dan material kerja yang berbeda, sedikitnya kalor yang diserap pada HE 2 disebabkan karena fungsi lain dari HE 2 sebagai jalur sirkulasi dari air yang berada di water drum boiler.

\section{KESIMPULAN}

Dari hasil penelitian ini dapat diambil beberapa kesimpulan sebagai berikut :

1. Koefisien perpindahan panas untuk masing-masing Heat Exchanger pada keadaan aktual dan komisioning ialah untuk HE1 $=0,598 \mathrm{~W} / \mathrm{m}^{2}{ }^{0} \mathrm{c}, \mathrm{HE} 2=0,829 \mathrm{~W} / \mathrm{m}^{2}{ }^{0} \mathrm{c}$, dan $\mathrm{HE} 3=0,799 \mathrm{~W} / \mathrm{m}^{2}{ }^{0} \mathrm{c}$ untuk aktual dan $0,8 \mathrm{~W} / \mathrm{m}^{2}{ }^{0} \mathrm{c}$ pada proses komisioning. Tidak ditemukannya perbedaan yang terlalu jauh pada nilai koefisien perpindahan panas menyeluruh untuk proses komisioning dengan proses selama penelitian. 
2. Jumlah kalor yang diserap untuk masing-masing heat exchanger pada keadaan aktual dan komisioning ialah untuk $\mathrm{HE} 1=88,515 \mathrm{KJ} / \mathrm{Kg}$ selama proses pengukuran aktual dan $11,99 \mathrm{KJ} / \mathrm{Kg}$ selama proses komisioning, $\mathrm{HE} 2=1,73 \mathrm{KJ} / \mathrm{Kg}$ selama proses pengukuran aktual dan 1,44 KJ/Kg selama proses komisioning, dan HE3=271,06 selama proses pengukuran aktual dan $72,82 \mathrm{KJ} / \mathrm{Kg}$ selama proses komisioning.

3. Perbedaan pada jumlah kalor yang diserap selama proses komisioning dan aktual salah satunya dapat disebabkan oleh berkurangnya panas yang dapat diserap pada masa preheater yang menyebabkan peningkatan penyerapan panas untuk setiap Heat Exchanger Furnace Boiler.

\section{SARAN}

Dari hasil penelitian, maka perlu diberikan beberapa saran antara lain :

1. Untuk mengurangi terjadinya pengikisan yang terjadi di Heat Exchanger di Furnace Boiler PLTU Nagan Raya agar diperhatikan penggunaan udara fludizing yang tidak berlebihan terlebih secara terus-menerus agar tidak mengikis pipa HE yang dapat menurunkan kinerja Boiler tersebut.

2. Memperhatikan bed material yang digunakan pada proses pembakaran sesuai dengan ukuran yang telah ditentukan agar tidak terjadi gesekan yang berlebihan antara pipa dan bed material.

3. Melakukan pembesihan secara berkala pada pipa-pipa Heat Exchanger di dalam Furnace Boiler untuk meningkatakan proses perpindahan panas yang terjadi dan mencegah terjadinya pengerakan atau slak.

\section{DAFTAR PUSTAKA}

1. D. Q. Kern, 1950, Process Heat Transfer, McGraw Hill, New York

2. Dec Henan Power Station Auxiliary Equipment Co., LTd, 2010, Boiler Operation Intruction, Manual Book, China

3. Djokosetyardjo. M.J. 2006. Ketel Uap. Jakarta : PT.Pradnya Paramita.

4. http://www.eprints.polsri.ac.id (14 oktober 2016)

5. Holman, J.P. 2002, Heat Transfer, Tenth Edition McGraw Hill, New York

6. Ir.Astu Pudjanarsa, MT. Dan Prof. Ir. Djati Nursuhud, MSME., 2006, Mesin Konversi Energi, Yogyakarta : Andi Offset

7. Koestoer, Raldi Artono, 2002, Perpindahan Kalor Untuk Mahasiswa Teknik, Ed. 1, Jakarta : Salemba Teknika.

8. Kreith, Frank, 1997, Prinsip-prinsip Perpindahan Panas, Ed. 3, Jakarta: PT. Gelora Aksara Pratama.

9. PT. PLN (Persero) Pusat Pendidikan dan Pelatihan. 2011. Termodinamika. Suralaya : PT. PLN (Persero).

10. Yao, Li. 2014. PLTU Nagan Raya NAD (2X110 MW) \#1 Boiler Performance Test Report. Nagan Raya : Sinohydro

11. Yendri, Efri. 2011. Boiler. Suralaya : PLN corporate university. 